\title{
Suppression of Human Growth Hormone Secretion
}

\section{by Melatonin and Cyproheptadine}

\author{
G. A. SMythe and L. Lazarus \\ From the Garvan Institute of Medical Research, St. Vincent's Hospital, \\ Sydney, N.S.W. 2010, Australia
}

\begin{abstract}
A B S T R A C T Pituitary growth hormone (GH) release in the rat is stimulated via serotoninergic pathways and can be inhibited by treatment with compounds that act as serotonin antagonists, such as cyproheptadine or the pineal gland hormone, melatonin. To investigate a possible role for serotonin in the control of human $\mathrm{GH}$ release, the effects of cyproheptadine and melatonin administration on the $\mathrm{GH}$ responses of normal male subjects were examined.

The oral administration of cyproheptadine (8-12 mg daily for 5 days) to normal subjects reduced their $\mathrm{GH}$ responses to both insulin-induced hypoglycemia and physical exercise to a highly significant extent. Similarly, the mean $\mathrm{GH}$ responses of 10 subjects to insulin-induced hypoglycemia were significantly reduced after the prior oral administration of melatonin $(1 \mathrm{~g})$.

The data presented show that serotonin antagonism has a similar effect on $\mathrm{GH}$ secretion in man to that observed in the rat and provides further evidence for serotoninergic, and possibly pineal, involvement in the control of human $\mathrm{GH}$ secretion.
\end{abstract}

\section{INTRODUCTION}

Evidence for brain catecholamine involvement in growth hormone $(\mathrm{hGH})^{1}$ secretion in man was first reported by Blackard and Heidingsfelder (1) who showed that the $\mathrm{hGH}$ response to insulin-induced hypoglycemia was influenced by $\alpha_{-}$and $\beta$-adrenergic blockade. Further indication that dopamine or norepinephrine may participate in the release of $\mathrm{hGH}$ was provided by Boyd, Lebovitz, and Pfeiffer (2) who showed stimulation of hGH secretion in patients with Parkinson's disease who were administered L-dopa. Many groups have since demonstrated

Received for publication 16 November 1973 and in revised form 22 February 1974.

1 Abbreviations used in this paper: GH, growth hormone; hGH, human growth hormone; 5-HTP, 5-hydroxytryptophan; 5-MT, $O$-methylserotonin. stimulation of hGH release in normal, nonobese subjects after L-dopa administration. However, Müller (3) has suggested that results on L-dopa stimulation of $\mathrm{hGH}$ secretion should be interpreted with caution because of the possibility that the effect of L-dopa may be due to final activation of serotoninergic receptors.

There is increasing evidence that serotoninergic pathways may have a more direct role in GH secretory mechanisms than catecholaminergic pathways. Imura, Nakai, and Yoshimi (4) recently demonstrated that hGH secretion is stimulated by relatively small doses of the serotonin (5-hydroxytryptamine) precursor 5-hydroxytryptophan (5-HTP), and, furthermore, on the basis of studies on patients with excess serotonin secretion (carcinoid syndrome), Feldman and Lebovitz (5) have suggested that serotonin may be a stimulator of hGH release. Collu, Fraschini, Visconti, and Martini (6) have demonstrated that intraventricular administration of serotonin causes $\mathrm{GH}$ release in the rat. Our studies (7-9) have shown that rat GH secretion is stimulated by intraperitoneal administration of 5-HTP and, furthermore, that it is inhibited by serotoninergic blockade and also by the pineal gland hormone, melatonin, which appears to act by competing with serotonin for serotonin receptor sites (9). The $\mathrm{GH}$ release observed in humans after the onset of slow-wave sleep (10) has also been suggested to originate via serotoninergic pathways $(3,11)$.

The present investigation was aimed at determining whether blockade of brain serotoninergic pathways or receptors in humans suppresses the hGH responses to stimulation and, consequently, at providing further evidence for serotoninergic control of $\mathrm{GH}$ secretion in man.

After the studies described herein were completed, Bivens, Lebovitz, and Feldman (12) reported that the $\mathrm{hGH}$ response to insulin-induced hypoglycemia was significantly suppressed by pretreatment with the serotonin antagonists cyproheptadine and methysergide. The 
conclusions presented by these workers provoked immediate comment and controversy $(13,14)$. The protocol employed by Bivens et al. (12) was similar to that used in one of the experiments presented in the present study, and thus a comparison of the findings is pertinent.

\section{METHODS}

These studies were performed on normal, informed nonobese male volunteers, aged 21-28 yr. All tests on the subjects began at 8:30 a.m. after an overnight fast. Blood samples were taken from an indwelling catheter in an antecubital vein. The patency of the catheter was maintained by a slow isotonic saline infusion. Blood samples were collected before stimulation and then every $15 \mathrm{~min}$ throughout the studies, and, except during the $20 \mathrm{~min}$ exercise regimen, each subject rested on a bed for the duration of each test. Tests on the same subject were carrid out at least 1 wk apart.

Study 1. Insulin-induced hypoglycemia control study. All 13 volunteers were subjected to this study. After collection of three basal blood samples, insulin (Novo Industri A/S, Denmark, neutral porcine crystalline; $0.1 \mathrm{U} / \mathrm{kg}$ ) was given intravenously at time " 0 " minutes. Blood samples were collected during the $2 \mathrm{~h}$ following insulin administration.

Study 2. Insulin-induced hypoglycemia after cyproheptadine administration. Seven of the subjects took part in this study. 5 days before the commencement of a second insulin hypoglycemia test, each subject began a regimen of oral cyproheptadine (Periactin, Merck, Sharp \& Dohme, West Point, $\mathrm{Pa}$.). On the 1 st and 2 nd days $4 \mathrm{mg}$ was taken twice daily and on the 3rd, 4th, and 5th days $4 \mathrm{mg}$ was taken three times daily. On the day of testing (6th day) a final $4 \mathrm{mg}$ was taken $1-2 \mathrm{~h}$ before commencement of the test so that the cumulative dose of cyproheptadine for the subjects completing the course was $56 \mathrm{mg}$. Due to severe side effects of the cyproheptadine experienced by one subject (extreme drowsiness) he was withdrawn from the study before completing the course. An insulin hypo glycemia test was then carried out on the remaining six subjects in an identical manner to that used in the control study.

Study 3. Exercise after cyproheptadine administration. The six subjects from study 2 (above) renewed oral cyproheptadine 2 days after the insulin hypoglycemia test and for 5 days followed an identical regimen to that above (i.e., $8 \mathrm{mg}$ for 2 days, then $12 \mathrm{mg}$ for 3 days). A final tablet $(4 \mathrm{mg}$ ) was taken $1-2 \mathrm{~h}$ before commencement of testing. After collecting basal blood samples the volunteers were subjected to a standardized physical exercise regimen consisting of $20 \mathrm{~min}$ pedaling on a bicycle ergometer (Monarch) at a load of 600 kilopondmeters $(\mathrm{kpm}) / \mathrm{min}$. The time of starting exercise was taken as $0 \mathrm{~min}$, and blood samples were collected during the following $2 \mathrm{~h}$.

Study 4. Physical exercise control study. After 1 wk without medication the six subjects from study 3 presented for a second exercise study to determine their control responses. Due to difficulties with venous catheterization, one subject was unable to be tested. The remaining subjects were given an identical exercise regimen to that of study 3 .

Study 5. Insulin-induced hypoglycemia after oral melatonin. This study group comprised 10 subjects. At 60 and $30 \mathrm{~min}$ before administration of insulin each subject was administered a $500-\mathrm{mg}$ capsule of synthetic melatonin (total $1.0 \mathrm{~g})$. Insulin $(0.1 \mathrm{U} / \mathrm{kg})$ was administered at time 0

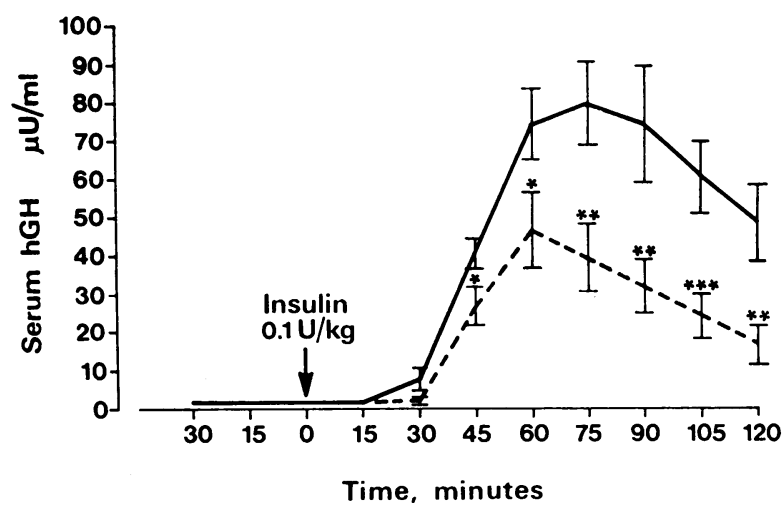

FIGURE 1 The effect of cyproheptadine on the serum hGH response to insulin-induced hypoglycemia in six normal subjects. The broken line shows their response after cyproheptadine and the continuous line shows their control response. Means \pm SEM are shown. The level of significance at different times is shown by asterisks: (*) $P<0.05$; (**) $P<0.025$; (***) $P<0.01$.

min using the same protocol as described in the control study.

Plasma glucose was estimated by a Technicon AutoAnalyzer (Technicon Instruments Corp., Tarrytown, N. Y.) using the ferricyanide method for reducing sugars. Serum $\mathrm{GH}$ was measured by the radioimmunoassay technique of Molinatti et al. (15), and the results are expressed in microunits of the WHO International Reference Preparation for hGH radioimmunoassay. Serum GH levels in control and test samples for each individual were estimated in the same assay. Statistical analysis was carried out using Student's $t$ test. Results are expressed as the mean \pm the SEM.

\section{RESULTS}

The serum GH response to insulin-induced hypoglycemia and the effect of cyproheptadine treatment on this response is illustrated in Fig. 1. Following cyproheptadine the mean serum hGH levels are significantly reduced at all times after 30 min. The mean peak level of hGH was earlier in the cyproheptadine study and was reduced from $90 \pm 15.0$ to $46.4 \pm 10.0 \mu \mathrm{U} / \mathrm{ml}(P<0.025)$. Cyproheptadine was found to also affect the hGH responses to physical exercise as illustrated in Fig. 2. While the subjects commented that they experienced greater difficulty in completing the exercise regimen with cyproheptadine treatment, their GH responses were markedly lower. One of the five subjects failed to show a rise in serum GH levels with exercise either on or off cyproheptadine, and his result was not included in the study. The other four subjects showed a normal response to the control exercise regimen, but two of these showed a peak serum response of less than $5 \mu \mathrm{U} / \mathrm{ml}$ with cyproheptadine. The small number of subjects completing this study prevented a high level of significance being obtained at individual sample times, but when the total amount of GH secreted by each subject was esti- 


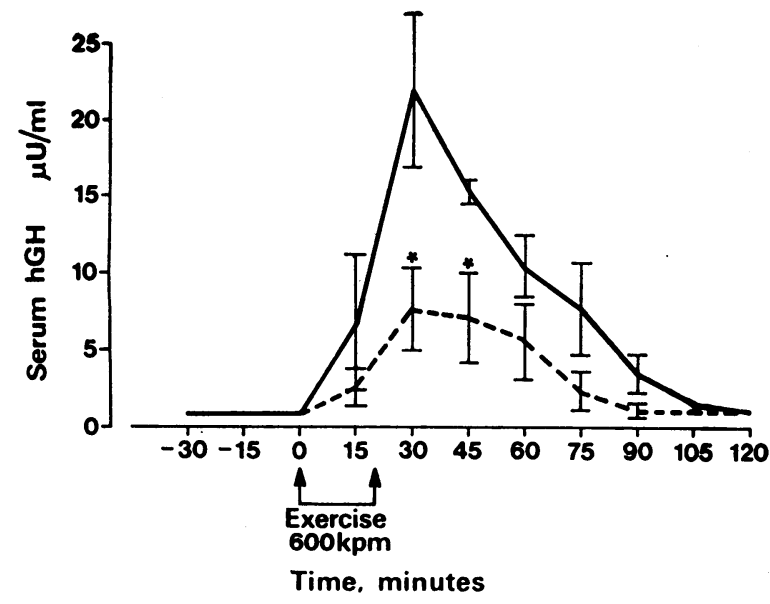

FIgURE 2 The effect of cyproheptadine on the serum hGH response to physical exercise in four normal subjects. The broken line shows their response after cyproheptadine and the continuous line their control response. Means \pm SEM are shown. (*) $P<0.05$.

mated by integrating the area under the individual response curves obtained with and without cyproheptadine, there was found to be a highly significant difference between the control and cyproheptadine treatment means for both the exercise and hypoglycemia studies. This is shown in Fig. 3. In the exercise study cyproheptadine treatment resulted in a reduction of approximately $50 \%$ in total hGH secreted over the time period covered $(P<0.0125)$.

The effect of melatonin administration on the $\mathrm{GH}$ response to insulin-induced hypoglycemia in the 10 sub-

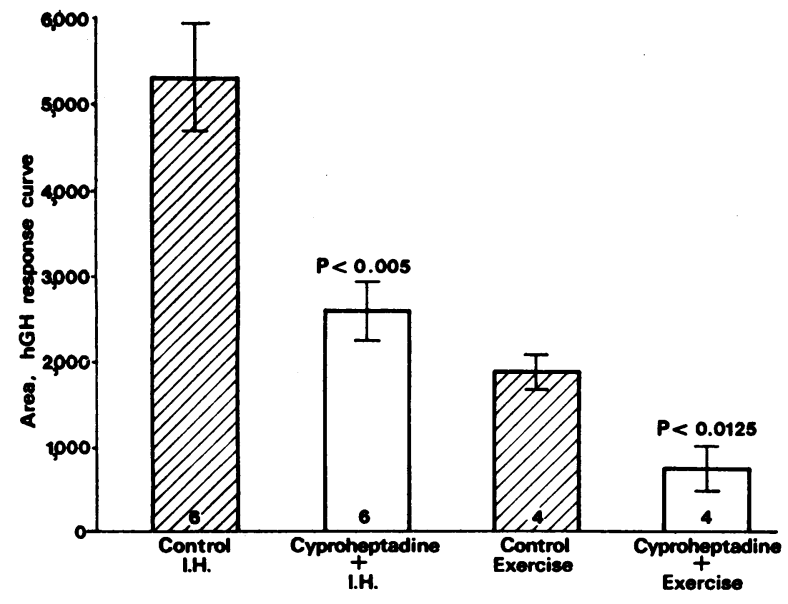

FIGURE 3 The effect of cyproheptadine on the mean integrated hGH responses to insulin-induced hypoglycemia (I. H.) and physical exercise in normal subjects. The bars represent the mean areas under the $\mathrm{GH}$ response curves for the $2 \mathrm{~h}$ after insulin administration on commencement of exercise. Means \pm SEM are shown. Units of area are microunits per minute per milliliter.

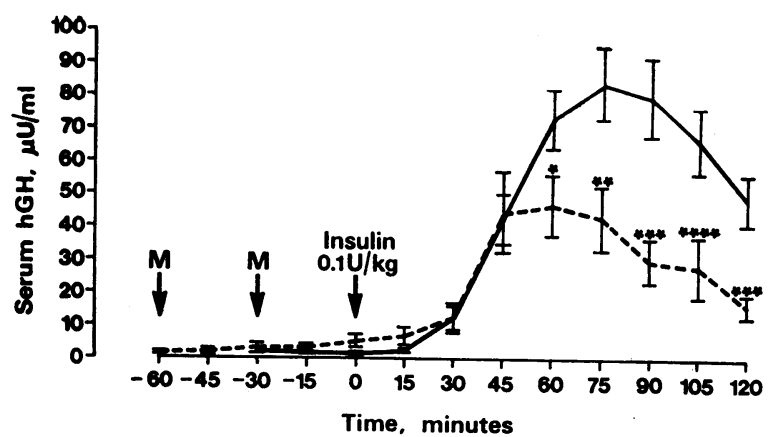

FIGURe 4 The effect of melatonin on the serum hGH response to insulin-induced hypoglycemia in 10 normal subjects. The broken line shows their response after $2 \times 500$ $\mathrm{mg}$ of melatonin (M) and the continuous line their control response. Means $\pm \mathrm{SEM}$ are shown. $\left(^{*}\right) P<0.05 ;$ (**) $P<^{*} P$ $0.01 ;(* * *) P<0.0025 ;(* * *)) P<0.005$.

jects tested is illustrated in Fig. 4. The GH response of only one subject failed to be suppressed by the melatonin. The mean GH response of all subjects was significantly reduced by $60 \mathrm{~min}$ and was reduced significantly at later sampling times. The mean peak hGH level for the 10 subjects was reduced from $94.7 \pm 12.8$ to $55.7 \pm 11.9 \mu \mathrm{U} / \mathrm{ml}$ $(P<0.025)$ with melatonin administration. The ability of melatonin to cause a small rapid paradoxical rise in serum GH levels 30 min after administration is seen in Fig. 4 at time 0 where the serum $\mathrm{GH}$ level for the melatonin study is significantly $(P<0.05)$ higher than that of the control study. Untoward side-effects were not noted after the melatonin administration.

Whereas both the cyproheptadine and melatonin regimens caused a significant alteration in the $\mathrm{GH}$ responses to insulin-induced hypoglycemia, neither treatment altered the degree of hypoglycemia achieved. This is shown in Table I.

\section{DISCUSSION}

The results of this investigation demonstrate that the oral administration of either the serotonin antagonist, cyproheptadine, or the pineal gland hormone, melatonin, result in a highly significant suppression of the normal $\mathrm{hGH}$ release after stimulation. The $\mathrm{hGH}$ responses to both insulin-induced hypoglycemia and physical exercise were significantly reduced by cyproheptadine treatment in all parameters measured. With the dose of cyproheptadine employed, the mean hGH responses were reduced by approximately $50 \%$. The inability of the cyproheptadine regimen to suppress completely the GH responses could indicate either that the GH response is only partly due to activation of serotonin receptors or, alternatively, that blockade of brain serotonin recep- 
TABLE I

The Degree of Hypoglycemia Induced by Insulin* after Cyproheptadine and Melatonin Administration in Normal Subjects

\begin{tabular}{|c|c|c|}
\hline Study & $\begin{array}{l}\text { No. of } \\
\text { subjects }\end{array}$ & $\begin{array}{c}\text { Fall in plasma } \\
\text { glucose, } \\
\text { mean } \pm \mathrm{SEM}\end{array}$ \\
\hline Insulin alone & 6 & $\begin{array}{l}m g / 100 \mathrm{ml} \\
54.6 \pm 3.8\end{array}$ \\
\hline Cyproheptadine and insulin & 6 & $54.5 \pm 3.1$ \\
\hline Insulin alone & 10 & $52.1 \pm 3.1$ \\
\hline Melatonin and insulin & 10 & $54.2 \pm 2.5$ \\
\hline
\end{tabular}

The mean basal fasting plasma glucose for all studies was $88.25 \pm 1.10 \mathrm{mg} / 100 \mathrm{ml}$ and all subjects were within $2 \pm \mathrm{SD}$ of this value at commencement of each test.

* $0.1 \mathrm{U} / \mathrm{kg}$.

tors was incomplete at the dose level of cyproheptadine selected. The results presented here showing suppression of $\mathrm{hGH}$ secretion by cyproheptadine are in excellent agreement with those presented by Bivens et al. (12) for insulin-induced hypoglycemia. Bivens et al. (12) proposed that the effect of cyproheptadine (and methysergide) was exerted at the level of the hypothalamus. This proposal provoked the suggestion by Essman, Sherman, and Kolodny (13) that these serotonin antagonists were unlikely to be able to exert a central effect, suggesting further that their actions were confined to peripheral receptor-site blockade of serotonin. However, we believe that there is ample evidence demonstrating that serotonin can cross the blood-brain barrier to exert central serotonin antagonism at doses well below the mean lethal dose (LD ${ }$ ) for laboratory animals. Van Riezen (16) has studied the pharmacological effects of cyproheptadine in mice, and in those parameters which are considered to involve serotonin receptors in the central nervous system, namely nialamide-induced hyperactivity and 5-HTP-induced head twitch and tremors, cyproheptadine exerted marked antagonism at doses as low as $1 \mathrm{mg} / \mathrm{kg}$ (representing $2.5 \%$ of the $\mathrm{LD}_{50}$ ). In a study of spinal neuronal activity using acute spinal cats, Banna and Anderson (17) have shown that small doses of cyproheptadine and methysergide completely inhibit the 5-HTP-induced increase in monosynaptic spike amplitude and spontaneous motoneural discharge. These neuronal responses to the serotonin antagonists were dose related but showed no correlation with their cardiovascular effects. The ability of cyproheptadine to inhibit hyperthermia produced by administration of bacterial pyrogen has been suggested by Feldberg (18) to be caused by its antagonism of serotonin at a hypo- thalamic level. Furthermore, we have shown (7) that, in the rat, serum GH levels already elevated by pentobarbital administration are rapidly suppressed to base-line levels by cyproheptadine treatment.

Thus, on the basis of this evidence we support the proposal by Bivens et al. (12) that cyproheptadine may exert its effects on $\mathrm{hGH}$ secretion by hypothalamic serotonin antagonism. However, we do not discard the possibility that cyproheptadine might act directly on the pituitary gland. Such a mechanism would imply that serotonin mediates in the release of $\mathrm{hGH}$ from the pituitary, and in this regard it is noteworthy that large concentrations of serotonin have been detected in the bovine pituitary gland and median eminence (19). Moreover, the pituitary gland has been shown to concentrate peripherally administered melatonin (20). The suppression of hGH after serotonin antagonism could thus be a consequence of an action at either or both the hypothalamus or the pituitary gland.

The effect of acute administration of melatonin on the $\mathrm{hGH}$ response to insulin-induced hypoglycemia was similar to that observed for cyproheptadine. Melatonin was selected as a possible inhibitor of brain serotonin receptors in this investigation and in studies on rat $\mathrm{GH}$ secretion (7-9) because it is an $O$-methylated derivative of serotonin. We have previously hypothesized (21) and recently shown $(22,23)$ that $O$-methylation of dopamine results in derivatives that inhibit the actions of dopamine by competing for its hypothalamic receptor sites. We subsequently proposed (24) that, by analogy with dopamine, $O$-methylated derivatives of serotonin such as $O$-methylserotonin (5-MT) and melatonin would antagonize the actions of serotonin at a receptor-site level. The structural relationships between dopamine and serotonin and their $O$-methyl derivatives are illustrated in Fig. 5.

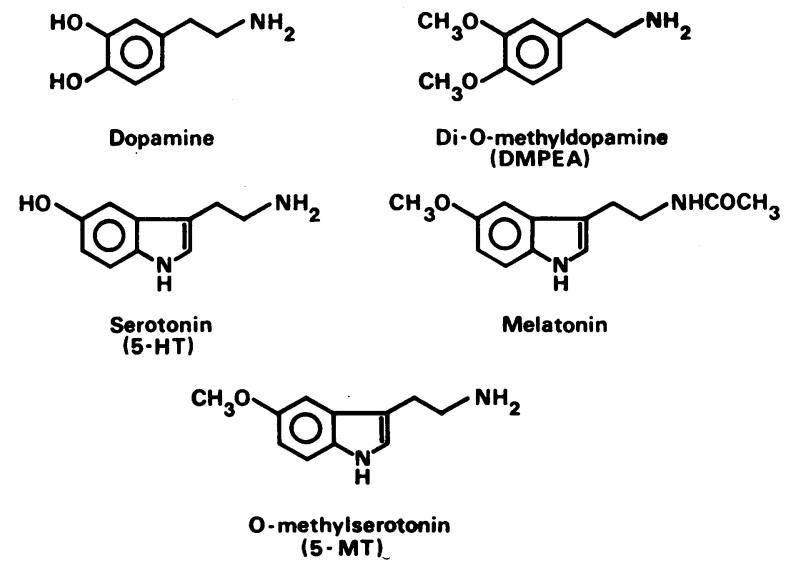

FIGURE 5 The structures of dopamine, serotonin, and their $O$-methylated derivatives. 
While oral administration of melatonin rapidly results in a small but significant elevation of serum hGH levels (25), the present data show this treatment to exert a significant inhibitory effect on the hGH response following insulin-induced hypoglycemia. We propose that the mean serum GH response after melatonin, shown in Fig. 4 represents a combination of two effects. First there is a stimulatory effect on serum hGH possibly reflecting initial activation of brain serotonin receptors by the melatonin (the early part of this effect can be seen in Fig. 4 where the GH response curve for the insulin-induced hypoglycemia study following melatonin is significantly higher than the control curve at time 0 ). Second, there is a subsequent blockade by melatonin of serotoninergic pathways normally activated by hypoglycemia. The net effect is significant suppression of the $\mathrm{hGH}$ response. The situation suggested is in concert with our proposal (9) that melatonin can act as a general blocker or competitive inhibitor of serotonin at its receptor sites. The findings explain the results of Starr (26) who reported decreased serum hGH levels in patients with sarcoma who were given long-term infusions of melatonin. The results for melatonin could also provide an explanation for the observation of Krieger and Glick (27) showing that blind human subjects do not exhibt slow-wave sleep-induced secretion of hGH. This phenomenon may be due to increased pineal synthesis and secretion of melatonin following blinding. Blinding or constant darkness results in a large increase in the activity of the melatonin-synthesizing enzymes in the rat pineal $(28,29)$, and recently it was shown (30) that the concentration of a melatonin-like substance increases in the plasma of humans kept in darkness.

The data of the present study do not allow us to say whether the observed effect of melatonin on GH secretion is pharmacological or wheher it reflects a physiological mechanism, but it does allow for the possibility of pineal involvement in the control of $\mathrm{GH}$ secretion from the pituitary gland.

The results of this investigation show that $\mathrm{GH}$ secretion in man is suppressed by serotoninergic blockade and thus provide further evidence for the involvement of serotonin in the neuroendocrine regulation of $\mathrm{hGH}$ release.

\section{ACKNOWLEDGMENTS}

The authors are indebted to their colleagues on the Garvan Institute staff for their skillful technical assistance and advice.

This work was supported in part by a grant from the National Health and Medical Research Council of Australia.

\section{REFERENCES}

1. Blackard, W. G., and S. A. Heidingsfelder. 1968. Adrenergic receptor control mechanism for growth hor- mone secretion. J. Clin. Invest. 47 : 1407-1414.

2. Boyd, A. E., III, H. E. Lebovitz, and J. B. Pfeiffer. 1970. Stimulation of human growth hormone secretion by L-dopa. N. Engl. J. Med. 283: 1425-1429.

3. Müller, E. E. 1973. Nervous control of growth hormone secretion. Neuroendocrinology. 11: 338-369.

4. Imura, H., Y. Nakai, and T. Yoshimi. 1973. Effect of 5-hydroxytryptophan (5-HTP) on growth hormone and ACTH release in man. J. Clin. Endocrinol. Metab. 36: 204-206.

5. Feldman, J. M., and H. E. Lebovitz. 1972. Control of insulin and growth hormone secretion by serotonin and dopamine. Excerpta Med. Int. Congr. Ser. 256: 35. (Abstr. 87.)

6. Collu, R., F. Fraschini, P. Visconti, and L. Martini. 1972. Adrenergic and serotoninergic control of growth hormone secretion in adult male rats. Endocrinology. 90: 1231-1237.

7. Smythe, G. A., and L. Lazarus. 1973. Suppression of growth hormone secretion by melatonin. J. Int. Res. Commun. 1(4): 13 .

8. Smythe, G. A., and L. Lazarus. 1973. Blockade of serotonin induced $\mathrm{GH}$ secretion in rats by melatonin and cyproheptadine. Horm. Metab. Res. 5: 227. (Abstr.)

9. Smythe, G. A., and L. Lazarus. 1973. Growth hormone regulation by melatonin and serotonin. Nature (Lond.). 244 : 230-231.

10. Takahashi, Y., D. M. Kipnis, and W. H. Daughaday. 1968. Growth hormone secretion during sleep. J. Clin. Invest. 47 : 2079-2090.

11. Laborit, H. 1972. Correlations between protein and serotonin synthesis during various activities of the central nervous system. Res. Commun. Chem. Pathol. Pharmacol. 3 : 51-81.

12. Bivens, C. H., H. E. Lebovitz, and J. M. Feldman. 1973. Inhibition of hypoglycemia-induced growth hormone secretion by the serotonin antagonists cyproheptadine and methysergide. N. Engl. J. Med. 289: 236239.

13. Essman, W. B., L. Sherman, and H. D. Kolodny. 1973. Growth hormone and serotonin antagonist. $N$. Engl. J. Med. 289: 870-871.

14. Bivens, C. H., H. E. Lebovitz, and J. M. Feldman. 1973. Growth hormone and serotonin antagonist. $N$. Engl. J. Med. 289: 871.

15. Molinatti, G. M., F. Massara, F. Pennisi, G. A. Scassellati, E. Strumia, and L. Vancheri. 1969. Radioimmunoassay of growth hormone. J. Nucl. Biol. Med. 13: 26-36.

16. Van Riezen, H. 1972. Different central effects of the 5-HT antagonists mianserine and cyproheptadine. Arch. Int. Pharmacodyn. Ther. 198: 256-269.

17. Banna, N. R., and E. G. Anderson. 1968. The effects of 5-hydroxytryptamine antagonists on spinal neuronal activity. J. Pharmacol. Exp. Ther. 162: 319-325.

18. Feldberg, W. S. 1968. The monoamines of the hypothalamus as mediators of temperature responses. In Recent Advances in Pharmacology. J. M. Robson and R. S. Stacey, editors. J. \& A. Churchill Ltd., London. 4th edition. 382-394.

19. Piezzi, R. S., F. Larin, and R. J. Wurtman. 1970. Serotonin, 5-hydroxyindoleacetic acid (5-HIAA), and monoamine oxidase in the bovine median eminence and pituitary gland. Endocrinology. 86: 1460-1462.

20. Wurtman, R. J., J. Axelrod, and L. T. Potter. 1964. 
The uptake of ${ }^{3} \mathrm{H}$-melatonin in endocrine and nervous tissues and the effects of constant light exposure. $J$. Pharmacol. Exp. Ther. 143 : 314-318.

21. Smythe, G. A., and L. Lazarus. 1973. The use of a hypothetical receptor-site model to predict novel pituitary hormone releasing and inhibiting agents. Excerpta Med. Int. Congr. Ser. No. 263. 189-197.

22. Smythe, G. A., and L. Lazarus. 1973. Blockade of the dopamine-inhibitory control of prolactin secretion in rats by 3,4-dimethoxyphenylethylamine (3,4-di-0-methyldopamine). Endocrinology. 93 : 147-151.

23. Smythe, G. A., L. Lazarus, and J. Finlayson. 1973 Dopaminergic control of prolactin secretion: structurefunction relationships. Proceedings 16th Meeting Endocrine Society of Australia. 16: 13.

24. Smythe, G. A., and L. Lazarus. 1973. Serotoninergic control of growth hormone secretion in the rat and in man. Proceedings 16th Meeting Endocrine Society of Australia. 16: 11.
25. Smythe, G. A., and L. Lazarus. 1973. The effects of cyproheptadine and melatonin on human growth hormone secretion. J. Int. Res. Commun. 1(10): 19.

26. Starr, K. W. 1970. Growth and new growth: environmental carcinogens in the process of human ontogeny. In Progress in Clinical Cancer. I. M. Ariel, editor. Grune \& Stratton, Inc., New York. 4: 1-29.

27. Krieger, D. T., and S. Glick. 1971. Absent sleep peak of growth hormone release in blind subjects: correlation with sleep EEG stages. J. Clin. Endocrinol. Metab. .33: $847-850$.

28. Wurtman, R. J., J. Axelrod, and L. S. Phillips. 1963. Melatonin synthesis in the pineal gland: control by light. Science (Wash. D. C.). 142: 1071-1073.

29. Klein, D. C., and J. L. Weller. 1972. Rapid light-induced decrease in pineal serotonin $\mathrm{N}$-acetyl-transferase activity. Science (Wash. D. C.). 177: 532-533.

30. Pelham, R. W., G. M. Vaughan, K. L. Sandock, and M. K. Vaughan. 1973. Twenty-four-hour cycle of a melatonin-like substance in the plasma of human males. J. Clin. Endocrinol. Metab. 37 : 341-344. 